\title{
The Reagan Effect: Self-presentation in humans and computers
}

ROLAND POSNER

In the sports section of a German newspaper we read:

It is a long and rocky road. But the world boxing champion Henry Maske appears to have already come a long way. The Light Heavyweight Champion says of himself: 'Now I am more like the Henry Maske that I really am'. (Der Tagesspiegel, December 11, 1993: 12)

The author of the article explains what Maske meant: 'The positive image that he has built up during his four short years as a professional boxer should now pay off'.

A fashion consultant instructs us: 'If I no longer know where I stand and why, I have to at least be standing in a positive light' (Sommer and Wind 1991: 213). He justifies this theoretically as follows:

The external presentation of the self no longer conveys 'I am such and such', but rather 'I could be such and such'. The expression becomes a simple impression. This is evidenced in politics: The politician simulates a person who is fighting for certain purposes, the professional simulates a person who has the profession that he or she is currently carrying out. Whether this is his/her profession is not important: What counts is the professional execution, the impressive performance.

A psychoanalyst writes about a colleague:

I have never met another analyst, who ... was more unavoidably himself than Donald W. Winnicott. This invulnerable way of being himself made it possible for him to be a different person to each of the most different kinds of people. Those who have met him had their own Winnicott. Winnicott never threatened the pictures that the others had made of him by trying to force his own way of being on them. And that is why he always remained so unyieldingly himself: Winnicott. (Khan 1977: 348)

Let me assume that you are willing to participate in a discourse of this type. Then you might ask yourself along with me: what does it mean 
'to be unavoidably oneself' - is not everyone this? How can 'being invulnerably oneself' lead someone to be seen differently by every other person? How can someone be 'unyieldingly himself' by not forcing 'his own way of being' on others?

These questions lay out the subject of the following deliberations. My topic is the self as a reality, that is, another's self as well as your own self. As you will see, the creation of a reality such as this involves selfpresentation and self-development, simulation and illusion. Therefore, I will examine in the first part of this paper the types of selves; in the second part, the kinds of presentation; and in the third part, the processes of self-presentation. In doing so, and in accordance with a successful strategy of artificial intelligence research, I will talk about people: people like you and me. I will generalize the results, however, so that they can be applied to all interactive cognitive systems. This will allow me to define the minimum requirements that a cognitive system must meet in order to develop a self.

To gain a clearer understanding, it is helpful to keep a specific person and a certain cognitive system in mind. In the latter case, just consider your PC and ask yourself how you would have to improve its hardware and software so that you could regard it as unavoidably, invulnerably, and unyieldingly being itself in the manner described by the psychoanalyst.

\section{Ronald Reagan as self-presenter}

As an example of a human cognitive system I have chosen a person, whom you all know through the media - the greatest self-presenter of the eighties: the stage performer, radio announcer, football reporter, movie star, labor leader, corporate spokesman, politician in the roles of Governor-maker, Governor of California (1967-1974), President of the United States (1980-1988), and elder statesman Ronald W. Reagan (shown in Plate 1 together with his wife, Nancy).

Does this person have a self at all? you might ask. Was he not a ball bounced around in changing contexts? Did he ever have a personality of his own? If he really did practice self-presentation, what was it that he presented? His own personality or the one that each different role provided him with: the role as an actor, as a reporter, as an official, as a politician?

As a public person, Reagan did not manage his self carelessly. He wrote (or had others write) two autobiographies and he encouraged a number of authors to write his biography. His first autobiography was titled Where's the Rest of Me? (1965) and the second, An American 


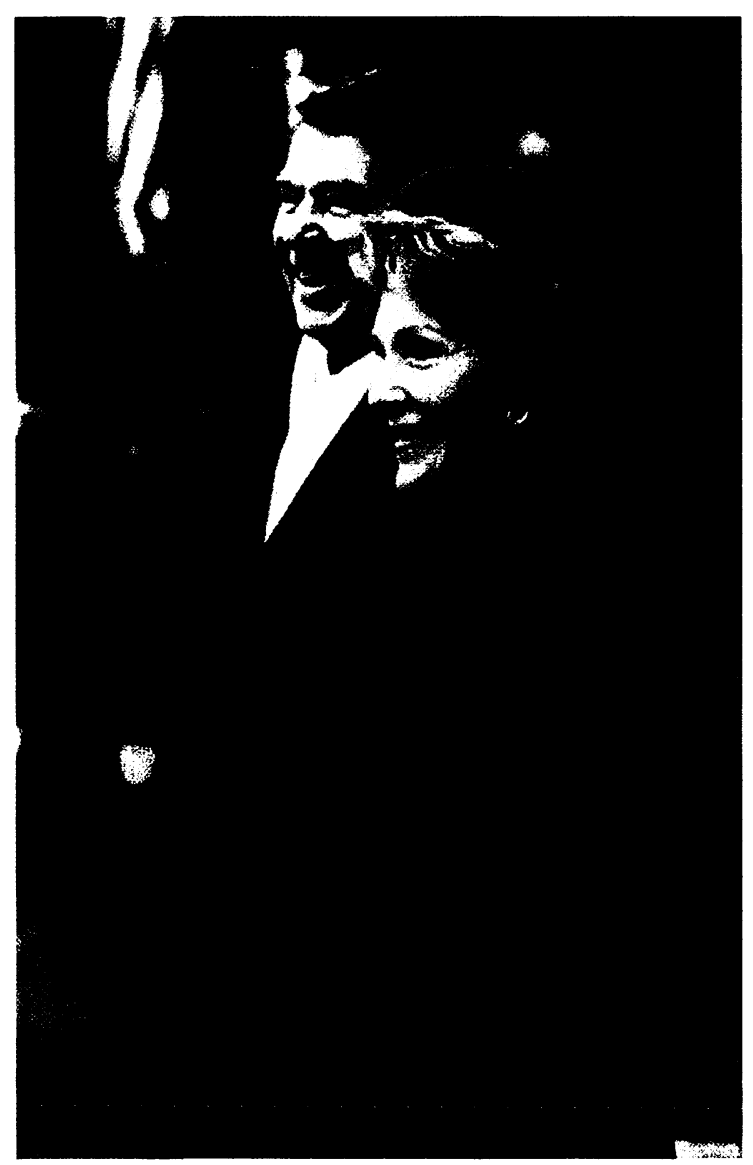

Plate 1. Ronald and Nancy Reagan 1984 (in Public Papers of the Presidents of the United States: Ronald Reagan, January 1 to June 29, 1984: i)

Life (1990). Both works tried to paint a coherent picture of him as a person, starting with his experiences as a youth and as an actor.

It is significant that in the title of his first autobiography, Reagan repeated a sentence that, when he said it in a movie, brought him high regard as an actor: 'Where's the rest of me?' The movie in question is King's Row, filmed in 1941, in which Reagan played Drake McHugh, a jovial young man from the countryside. McHugh lost his money during the Great Depression, took on a job as a railroad worker, had an accident and fell into the hands of the surgeon Dr. Gordon. Gordon's daughter was one of Drake's girlfriends and Gordon had already done 


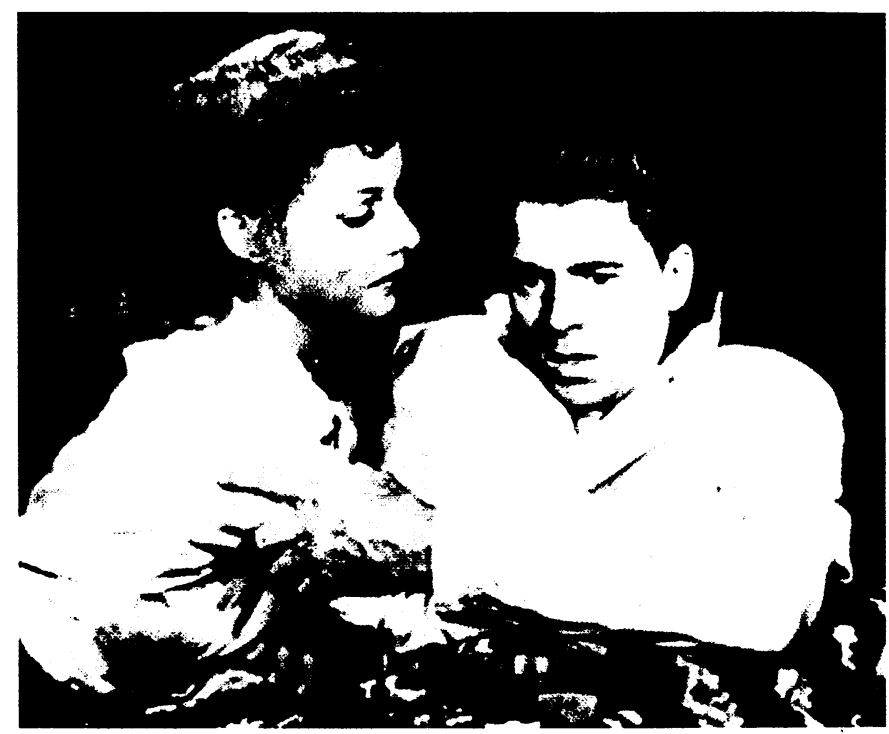

Plate 2. After the operation, Drake calls his wife and asks her desperately: 'Randy, where's the rest of me?' Ronald Reagan as Drake McHugh in the movie King's Row (USA 1941, director: Samuel Wood; photograph: Stiftung Deutsche Kinemathek, Berlin)

everything he could to change his daughter's mind about wanting to marry Drake. Although, in the meantime, Drake had married another woman, Gordon still resented him so much that he unnecessarily amputated both of Drake's legs at the hips. When Drake awoke from the anaesthesia, he felt for his legs, called his wife, and cried: 'Randy, where's the rest of me?' Reagan succeeded in portraying Drake so well in this scene that he was nominated for an Oscar (see Plate 2).

Drake's question 'Where is the rest of me?' referred both to his physical and mental self. His body had been mutilated, making it impossible for him to continue living as before. In the first paragraph of his 1965 autobiography, Reagan writes that his mother, upon seeing her newborn baby in February 1911, had said faintly: 'I think he's perfectly wonderful' (Reagan 1965: 3). Down further on the same page, he writes: 'It was not until thirty years later that $I$ found part of my existence was missing.' Credibly portraying someone who was no longer complete, someone who had lost part of himself, presented Reagan 'with the most challenging acting problem in ... [his] career' (Reagan 1965: 4).

Yet, what is this self if it is possible to lose part of it without losing oneself? This question is answered later on in the movie. Drake's wife, Randy, and his friend Perry carefully kept it a secret from him that he 


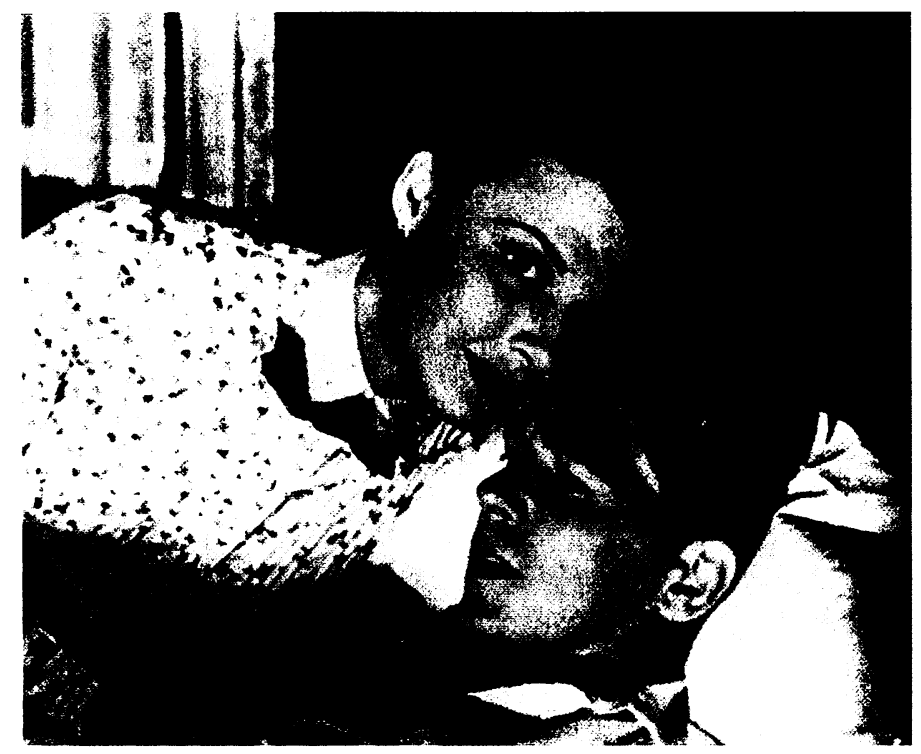

Plate 3. Drake: 'Where did Gordon think I live, in my legs? Did he think those things were Drake McHugh?' Randy: 'He wanted to destroy the Drake McHugh you were.' Taken from the movie King's Row (USA 1941, director: Samuel Wood; photograph: Stiftung Deutsche Kinemathek, Berlin)

had become the victim of a crime. They thought this discovery would kill him. One day, however, as Drake threatened to fall into a deep depression, Perry, who was a psychoanalyst, changed his mind. $\mathrm{He}$ believed that, in the long run, his friend could only be helped by hearing the truth. If Drake was still entirely himself, then he would be able to cope with this terrible reality.

After hearing Perry's horrible news, Drake underwent an amazing change of attitude. Gradually, he smiled and then said contemptuously: 'Where did Gordon think I live, in my legs? Did he think those things were Drake McHugh?' (see Plate 3).

Drake's condition improved from the moment that he ceased to equate his body with his self and a part of his body with a part of his self: 'I lost my legs, okay, but now I've found myself again,' he says contemplatively, 'I'm still myself as much as ever.' Triumphantly, he continues: 'The old Drake is there again. Where's the rest of me? There is no rest of me. I'm as perfect as I ever was.'

Soon the question of his self-completeness was to preoccupy Ronald Reagan not only in his virtual life but in his social and personal lives as well. People did not want to take Reagan, the actor, seriously as 
a politician. Reagan (1965: 6) explains: 'So much of ... [the actor's] profession is taken up with pretending ... .' This leads people to say of him: 'He is only an actor.' That is, 'he is much like I was in King's Row, only half a man' (1965: 6). And Reagan agrees with them. He, himself, felt at times 'I had become a semi-automaton "creating" a character another had written, doing what still another person told me to do on the set' (1965: 6). Therefore, as he became involved in politics, Reagan had to develop a strategy to deal with the accusation: 'If you're an actor, the only thing you can do is act. ... that's all you can do: pretend' (Reagan 1990: 151). He had to invalidate the suspicion that he only 'memorizes speeches written by other people, just like he memorized the lines that were fed to him by his screenwriters in the movies' (1990: 151).

Reagan was able to find a way out of his predicament that was as simple as it was effective: he tried to present himself as he was. At the beginning of his political career, Reagan reduced his speeches to a few introductory words and then held a question-and-answer session directly with the audience (Reagan 1990: 151). In order to show who he was, he had to react immediately and be quick-witted. He did this by acquiring a supply of jokes that could be used flexibly and by telling stories from his own life. The content of his message was not very important. Nor did its delivery have to be especially refined. Important was that the performer appeared to be true to himself in the various contexts, i.e., that the content of his message remained constant. In politics, it was never his own impression but rather that of the audience that determined whether his performance was a success or a failure. And this determined which aspects of his behavior he developed further. Thus, the audience determined Reagan's self. Like a leitmotif, this experience recurs throughout the autobiography.

Reagan describes events from his youth to document with gratitude how others have made him what he is (see Plate 4). He writes that his mother 'had the conviction that everyone loved her just because she loved them' (Reagan 1965: 9). This notion rubbed off on Ronnie, as he was called then.

That Ronnie started and succeeded at acting can also be attributed to others. When he was nine years old, his parents moved with him and his older brother to the small country town Dixon. There, his mother joined a group that staged recitals of plays and other literary works. Reagan (1990: 35) remembers:

One day she helped me memorize a short speech and tried to persuade me to present it that evening at a reading, but I resisted. My brother had already given 


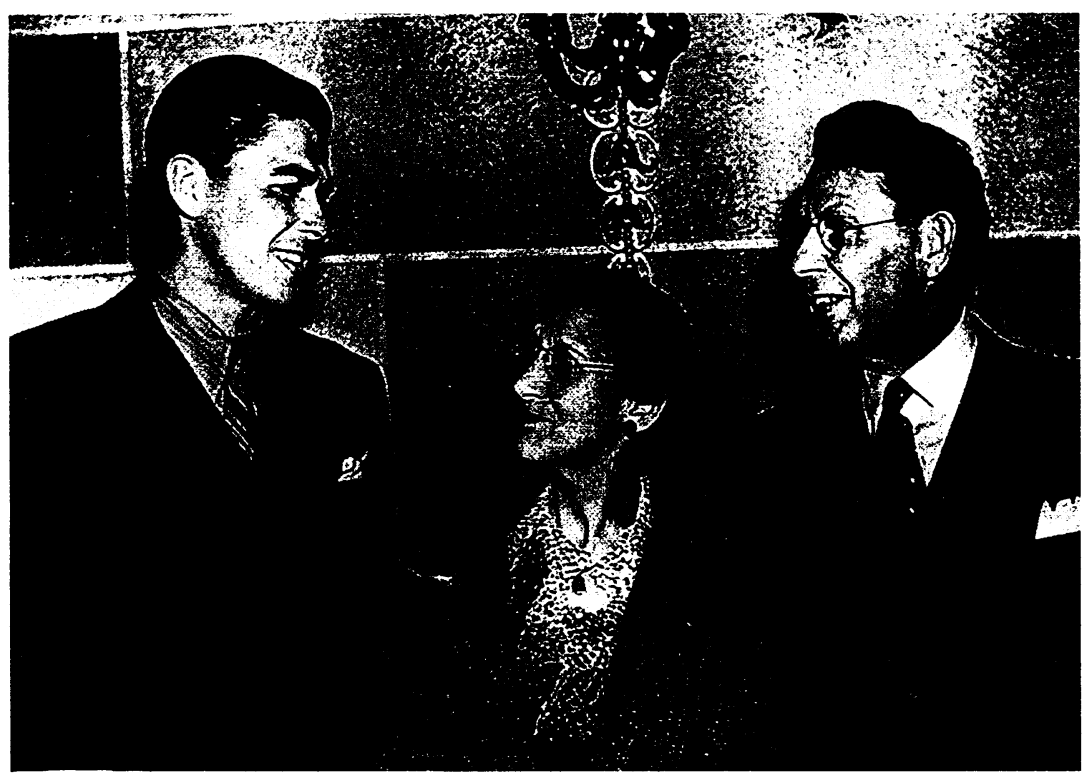

Plate 4. Reagan, the actor, with his parents (Reagan 1990: Fig. 5)

several and had been a hit; in fact, he could sing or dance with the best of 'em and a lot of people in Dixon thought he'd end up in show business. But I was more shy and told my mother I didn't want to do it. Yet I guess there was something competitive enough in me that made me want to try to do as well as my brother and I finally agreed. Summoning up my courage, I walked up to the stage that night, cleared my throat, and made my theatrical debut. I don't remember what I said, but I'll never forget the response: People laughed and applauded. That was a new experience for me and I liked it. I liked that approval. For a kid suffering childhood pangs of insecurity, the applause was music. I didn't know it then, but, in a way, when I walked off the stage that night, my life had changed.

Reagan reports many other such critical events in his life, and all show how much other people's opinions influenced his own opinion of himself. At college, he was a member of the drama society. Reagan (1990: 58) describes the group's delight when it placed second in a competition that took place at another university:

while we were relishing this success, it was announced I was one of three performers who had been selected to receive individual acting awards. Afterward, the sponsor of the contest called me into his office and inquired if I'd ever thought about making acting my career. I said, 'Well, no,' and he said, 'Well, you should'. 


\section{Reagan comments:}

I guess that was the day the acting bug really bit me, although I think it was probably orbiting pretty close to me for a long time before that.

There are, however, some disadvantages to being dependent on other people's opinions. For example, Reagan repeatedly ran into trouble as a radio announcer. He writes (Reagan 1965: 56):

The secret of announcing is to make reading sound like talking. I still am not good at a first reading of a script. At that time I was plain awful. I knew it, and so did the listeners. What was worse, so did the sponsors. I couldn't give it that easy conversational persuasive sell.

The constant refraction of self-perception through the perception of others will remain my topic. It comes to a point with the question: to what extent is a person that which the others consider him/her to be?

\section{The types of selves}

Let us now try to answer the questions regarding the self and selfpresentation by embedding them in semiotic theorization. These questions then become: How much of the self depends on self-presentation? What type of sign process is self-presentation?

In order to answer these questions, we need to first examine a series of notions of self. I will explain these using examples from young Reagan's life (and allow myself to expand on his biography a bit).

\section{The personality (the self in the narrow sense)}

Let us consider the Reagan family. The father, who was constantly looking for work, had to once again move with his family to another town. In this unfamiliar town, young Ronnie was placed in a second grade class with a teacher who did not know him. The teacher wanted to see how well he could write his name. Ronnie wrote 'Ronald' in his best handwriting on the board. The teacher saw this and said in front of the whole class: 'You are a fine writer.'

This one action $f$ (the act of writing finely) of the student $b$ prompts the teacher $a$ to attribute a characteristic $F$ (fine writer) to $b$.

(1a) $\quad T(b, f)$

[b performs fine writing] 
(1b) $\quad F(b)$

[ $b$ is a fine writer]

In this manner, being a fine writer attains the status of a permanent feature, a personality trait. The teacher construes Ronnie's self as the set $\{\ldots\}$ of such personality traits $P$. Accordingly, let us take the 'personality' of the person $b$ to be the set of $b$ 's personality traits:

(S1)

$$
\{P \mid P(b)\}
$$

[the set of all $P$ for which $P(b)$ is true]

During the Enlightenment, psychologists considered the self to be a personality in this sense. This notion served as a theoretical basis for the theatrical work of authors such as Friedrich Schiller. As is well known, Schiller studied the criminology of his time. He wrote his own pieces according to the principle that the audience should infer the offender's character from his/her actions. In his fifth 'Brief über die Ästhetische Erziehung des Menschen' ('Letter on the aesthetic education of man') Schiller maintains (1962 [1795]: 580): 'People portray themselves through their actions'. In order to treat one another fittingly, we all try to attribute lasting characteristics to each other in the form of personality traits; these attributions are made on the basis of behavior observed on only a few occasions.

\section{The self-concept (the self-conceived self)}

The teacher was a figure of authority to young Ronnie. Through the teacher's praise, Ronnie felt himself approved of and came to think of himself as a fine writer. Whenever he wrote something on the blackboard, he wrote it as finely as he could:

(2a) $\quad T(b, f)$

$[b$ does $f]$

because he believed, that he was a fine writer:

(2b) $\quad G(b, F(b))$

$[b$ believes that $b$ is an $F]$

Being able to produce fine writing was now a part of $b$ 's self-concept, part of what he believed himself to be.

Accordingly, we define $b$ 's 'self-conceived self' to be the set of all permanent features $P$ which $b$ believes to be his personality traits:

(S2)

$\{P \mid G(b, P(b))\}$

[the set of all $P$ of which

$b$ believes that $P(b)$ is true] 
In attribution psychology, the self-conceived self is termed 'self-concept' and is a notion used in studying the self (see Gergen 1971; Epstein 1979; Mummendey 1990).

\section{The image (the other-conceived self)}

The ability that the teacher discovered in Ronnie gave him several advantages: when it came time to write sentences on the board, the teacher gladly called on Ronnie and the other students gave Ronnie precedence. They did this because they believed that Ronnie could do the job best. They considered him to be a fine writer:

(3) $\quad G(a, F(b))$

[ $a$ believes that $b$ is an $F$ ]

Ronnie's classmates had a certain idea about him. Fine writing was part of their image of him.

In contrast to the 'self-conceived self,' let us call this image $b$ 's 'otherconceived self.' It is defined as the set of permanent features $P$ which the others $a$ believe to be $b$ 's personality traits:

(S3) $\quad\{P \mid G(a, P(b))\}$

[the set of all $P$ of which

$a$ believes that $P(b)$ is true]

William James (1890) called a person's other-conceived self the 'social self', and George Herbert Mead analyzed it as such in extensive publications (1934 and 1964).

The self-wish (the self-intended self)

Despite all of the advantages, after a while Ronnie felt that his roles as a fine writer and the teacher's pet were too limited. He wanted to prove himself a success outside of the classroom, too. Thus, he tried to become a good swimmer.

(4) $\quad I(b, F(b))$

[ $b$ wants $b$ to be an $F$ ]

He did not find this difficult, either. He would often jump into the river and swim against the current. He swam under water and was pleased that he could hold his breath over increasingly long distances.

The wish to be a good swimmer is an example of what we call a 'selfintended self.' In contrast to the 'self-conceived self,' we define $b$ 's 'self-intended self' as the set of permanent features $P$ that $b$ wishes to have as personality traits. 
(S4)

$$
\{P \mid I(b, P(b))\}
$$

[the set of all $P$ for which

$b$ wants $P(b)$ to be true]

Many of the features which make up a person's self-intended self (S4) can be made features of the personality, i.e., of the self in the narrow sense (S1), by 'working on one's self'.

\section{The other-wish (the other-intended self)}

Ronnie's classmates also desired certain things of him. They wanted him to play with them after school without getting angry if he lost. They wished that Ronnie were a fair player.

(5) $\quad I(a, F(b))$

[ $a$ wants $b$ to be an $F$ ]

Since this was still difficult for Ronnie, he had a hard time in his class.

The others' desire that a person possess a certain personality trait is part of what we call this person's 'other-intended self'. In contrast to the 'selfintended self', we define the 'other-intended self' as the set of permanent features $P$ that the others $a$ would like $b$ to have as personality traits:

$$
\begin{aligned}
& \{P \mid I(a, P(b))\} \\
& \text { [the set of all } P \text { for which } \\
& a \text { wants } P(b) \text { to be true] }
\end{aligned}
$$

The image-concept (the self-conceived other-conceived self)

If we compare what Ronnie was (his self in the narrow sense, S1) with what he believed himself to be (his self-conceived self S2), what he wanted to be (his self-intended self S4), what the others believed Ronnie to be (his other-conceived self S3), and what they wanted him to be (his otherintended self S5), there are many possibilities for concurrence and difference. There are no problems if what a person is is the same as what the others believe and want him/her to be. However, this is rarely the case for all personality traits, which Ronnie, too, came to experience. $\mathrm{He}$ considered himself to be a good football player:

(6a) $\quad G(b, F(b))$

[ $b$ believes that $b$ is an $F$ ]

When it came time to choose players for the class team, however, Ronnie's fellow students preferred others to him:

(6b) $\quad G(a, \neg F(b))$

[ $a$ believes that $b$ is not an $F$ ] 
Ronnie came to realize that his classmates' image of him as a football player did not correspond with his image of himself:

(6c) $\quad G(b, G(a, \neg F(a)))$

[ $b$ believes that $a$ believes that

$b$ is not an $F$ ]

In situations such as this, Ronnie constructed his own concept of the others' concept of himself. That is, he constructed his self-conceived other-conceived self. In other words, he thought about his classmates' image of himself and developed a certain image-concept. 'It has taken me many years to get used to seeing myself as others see me ...,' Reagan later wrote in his autobiography (1965: 79).

We define $b$ 's 'self-conceived other-conceived self' as the set of permanent features $P$ of which $b$ believes that the others $a$ think that they are $b$ 's personality traits, i.e., which $b$ believes to belong to his other-conceived self:

(S6)

$$
\{P \mid G(b, G(a, P(b)))\}
$$

[the set of all $P$ such that $b$ believes that

$a$ believes that $P(b)$ is true]

The self-conceived other-conceived self is what the psychiatrist Ronald Laing (see Laing 1960 and in particular Laing, Phillipson, and Lee 1966: part I, chs. 2 and 3) called the 'meta-image' of a person. A person's metaimage (image-concept) can differ from his/her image (other-conceived self) as well as from his/her self-concept and personality traits (self in the narrow sense). Ronnie was, in fact, an average football player, but at times he considered himself to be a football genius; and sometimes he thought that the others regarded him as a failure, whereas they actually considered him to be just average.

\section{The image-wish (the self-intended other-conceived self)}

What could a schoolboy like Ronnie do to improve his image as a football player? He practiced diligently and took advantage of every opportunity he got to play football well in front of the others.

(7a) $\quad T(b, f)$

[b plays good football]

He did this with the intention of creating situations which would lead the others to believe that he was a good football player:

(7b) $\quad I(b, E(f) \rightarrow G(a, F(b)))$

[ $b$ wants playing good football to cause $a$ to believe that

$b$ is a good football player] 
Whoever behaves in this manner is trying to fulfill an image-wish. Technically speaking, what is meant here is a self-wish for an other-conceived concept of one's self, i.e., a self-intended other-conceived self.

A person's 'self-intended other-conceived self' is defined as the set of permanent features $P$ of which $b$ wants the others $a$ to believe that they are $b$ 's personality traits (i.e., which $b$ wants to be part of his other-conceived self):

$$
\{P \mid I(b, G(a, P(b)))\}
$$

[the set of all $P$ such that $b$ wants

$a$ to believe that $P(b)$ is true]

However, tending to one's image in this way carries the risk that the opposite of the intended effect is achieved: the others consider one to be a show-off rather than a good football player.

The image-wish image (the other-conceived self-intended other-conceived self)

The Ronnie of old actually did exaggerate his image-correction efforts. $\mathrm{He}$ not only wanted to be an exemplary swimmer, he also wanted to be regarded as a good football player. That he continuously tried to bring this about bothered his classmates. They developed a concept of his desire to show off, i.e., an other-conceived concept of his image-wish emerged. Playing good football in so obtrusive a manner not only caused his classmates to believe that he was a good football player, as was intended:

(8a) $\quad E(f) \rightarrow G(a, F(b))$

[playing good football causes $a$ to believe that

$b$ is a good football player]

It also caused his classmates to believe that Ronnie wanted them to believe that he was a good football player, which was not intended:

(8b) $\quad E(f) \rightarrow G(a, I(b, G(a, F(b))))$

[playing good football causes $a$ to believe that

$b$ wants $a$ to believe that

$b$ is a good football player]

In this manner, Ronnie became a braggart. His positive personality traits paled in the light of the supposition that he developed these traits only to show them off to the others. A supposition such as this is an example of an image-wish image. Technically speaking, it is what we call an 'other-conceived self-intended other-conceived self':

(S8) $\quad\{P \mid G(a, I(b, G(a, P(b))))\}$

[the set of all $P$ such that $a$ believes that

$b$ wants $a$ to believe that $P(b)$ is true] 


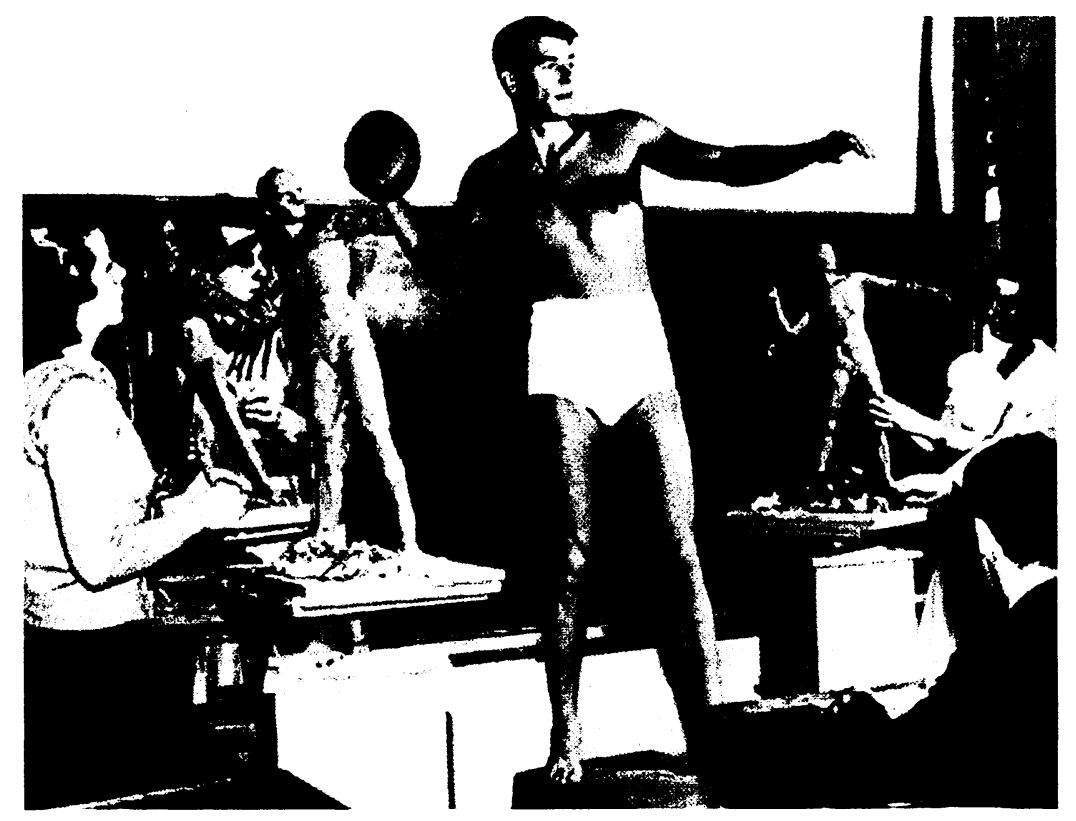

Plate 5. Reagan posing as a football player for a sculpturing class at the University of Southern California (photograph: Friedman 1986: 37). The movie company Warner Brothers marketed Reagan in this way as the 'Twentieth-Century Adonis' having 'the most nearly perfect male figure in Hollywood'

Being considered a show-off is not a good image, and Ronnie knew how to counter this. Which notion of self this would entail is now left to the reader to determine.

Plate 5 illustrates yet another notion of self: the 'other-intended otherconceived self'. The production company Warner Brothers wanted the public to believe that Reagan was a 'Twentieth Century Adonis'.

\section{The stratified total-self}

Theoretically, this exposition of 'self' notions could continue indefinitely. I would like to stop here, however, in order to summarize the definitions of the self which have been introduced thus far:

S1: the self in the narrow sense

S2: the self-conceived self

S3: the other-conceived self

S4: the self-intended self 
S5: the other-intended self

S6: the self-conceived other-conceived self

S7: the self-intended other-conceived self

S8: the other-conceived self-intended other-conceived self.

On comparing these definitions, we realize that each type of self contains a set of features $P$ which are ascribed to a person $b$ either directly or by way of belief or intention. In the formulas (S1) through (S8), $G(\ldots, \ldots)$ stands for 'believe' and $I(\ldots, \ldots)$, for 'intend'. In the examples, the verbs thinks, assumes, regards, and considers were sometimes substituted for 'believes', and 'intends' was occasionally replaced by wants, desires, and wishes. The extent to which an ascribed feature is embedded in belief and intention can be increased at will. As shown by the examples, it depends on the complexity of the situation that has to be managed by the person and the others concerned. (A systematic list of all 'self' notions involved can be found in Posner 1996.)

As a result, an open set of selves of arbitrary complexity can be constructed. Every person has several selves. It is the entire set of selves developed by a person at some time or another that I propose to call the 'total-self' of that person (see Fig. 1).

The person $b$ 's maximum total-self can be represented by the formula: (GS) $\quad\{P \mid \ldots P(b)\}$

[the set of all $P$ for which $\ldots P(b)$ is true]

The dots in the formula can be replaced by operator sequences of optional complexity; the operators are of the type $G(\ldots)$ or $I(\ldots$, - their closing parenthesis being placed before the rightmost bracket. As a result, GS generates the set of b's sub-selves, S1, S2, ... S8, etc.

Every total-self can be organized as in Figure 1 by assigning the sub-selves to different levels of reflection. The structure by which the personality-trait formulas are embedded in formulas of belief and intention serves as the assignment criterion.

A state of affairs which does not include believing or intending is assigned to the reflection level RS0. The self in the narrow sense, S1, is a set of features of this type: $\{P \mid P(b)\}$. S1, thus, belongs to reflection level RS0.

A state of affairs which consists in believing or intending a state of affairs on RS0 is assigned to the reflection level RS1. The self-conceived self, S2, is a set of features on level RS0 which the person believes to be his/her own: $\{P \mid G(b, P(b))\}$. The other-conceived self, $\mathrm{S} 3$, is a set of features on level RS0 which the others believe to be features of the person concerned: $\{P \mid G(a, P(b))\}$. The self-intended self, S4, is a set of features on level RS0 which the person concerned intends to possess: $\{P \mid I(b, P(b))\}$. The other-intended self, S5, is a set of 


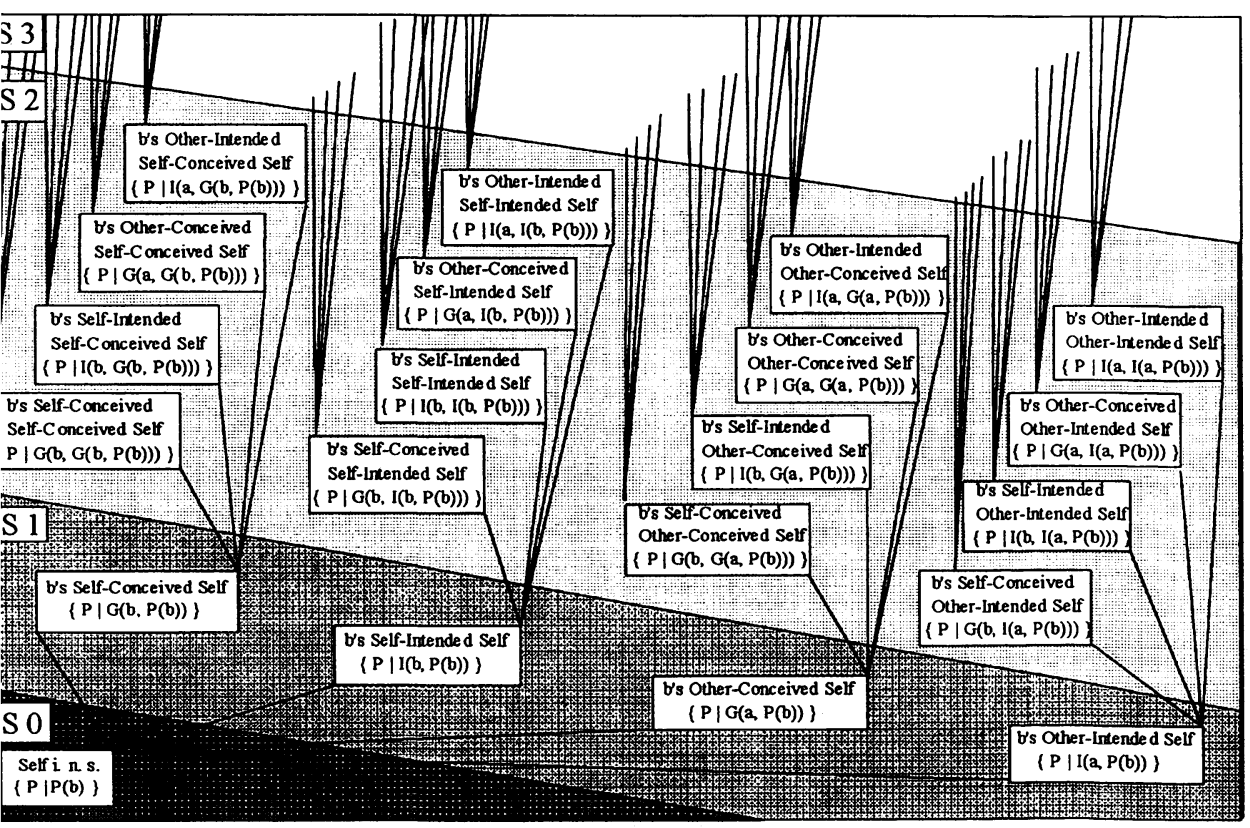

Figure 1. The stratified total-self with its sub-selves at the reflection levels $R S O, R S 1, R S 2$, etc.

features on RS0 which others intend $b$ to have: $\{P \mid I(a, P(b))\}$. Thus, the selves S2 through S5 belong to reflection level RS1. This is made clear by the structure of the expressions to the right of the vertical slashes.

A state of affairs which consists in believing or intending a state of affairs on level RS1 is assigned to the reflection level RS2. The selfconceived other-conceived self, S6, is a set of features on RS1 which the person concerned believes to be true: $\{P \mid G(b, G(a, P(b)))\}$. The self-intended other-conceived self, S7, is a set of features on level RS1 which are intended by $b:\{P \mid I(b, G(a, P(b)))\}$. Thus, the selves S6 and S7 belong to reflection level RS2. Further selves on this reflection level are shown in Figure 1.

The other-conceived self-intended other-conceived self, S8, is a set of features on level RS2 which the others believe to be true: $\{P \mid G(a, I(b, G(a, P(b))))\}$. S8, thus, belongs to reflection level RS3.

We call a total-self that has been divided into the different levels of reflection, as was done here, a 'stratified total-self'. As shown by the examples taken from young Reagan's life, during self-presentation, a person is less focussed on his/her total-self than on a specific sub-self. 
The 'self' notions discussed here identify what is actually being presented when a person tries to present him/herself. This answers our first question, allowing us to now turn to the possible kinds of presentation so that we can then determine what may be regarded as self-presentation.

\section{Kinds of presentation}

In discussing the types of selves, I have used configurations of the notions of 'feature', 'intending', and 'believing'. These same notions can be used to answer questions regarding the process we call 'presentation'. Each presentation is a sign process, and whoever produces signs does something with the intention that it cause others to believe something. Self-presentation, then, occurs when that which the others are to believe concerns a self-feature of the person who would have them believe it.

By making use of the notions of 'believing' and 'intending', as well as the notion of causality ('causing'), we can not only explain the types of selves but also the structure of the sign processes involved. Given this foundation, it is even possible to systematize all conceivable types of sign processes (see Posner 1993 and 1995).

In the current context, our task is to outline the types of sign processes only insofar as they underlie the various kinds of presentation. With this goal in mind, we return to the small country town of Dixon, where Ronald Reagan spent part of his youth, and try to look at it from his perspective.

\section{The indicator}

In Dixon there was an area where weekend houses stood that were usually vacant during the week. Ronnie liked to wander around there. While looking at one of the houses, he noticed that a window was open. This led him to believe that the house was occupied:

$$
\begin{aligned}
& E(f) \rightarrow G(a, p) \\
& \text { [The occurrence of } f \text { causes } \\
& a \text { to believe that } p \text { ] }
\end{aligned}
$$

In that the opened state of the window suggested to him that the house was occupied, it became an indicator for Ronnie. We are dealing here with what is called an 'indicator process'. Indicators are circumstances which cause a person to assume a certain state of affairs to exist. We call the person affected by the indicator a 'recipient'. That which is believed is called the 'message'. Indicators require neither that the believed 
message is true nor that a person (a sender) exists who intends to cause this belief.

\section{The indicator production}

As Ronnie was wandering in the area again, an attic window of one of the houses opened. Ronnie noticed the window opening. This led him to believe that the house was occupied. This time, there was a person $b$ who produced the circumstance which caused another person to assume a certain state of affairs to exist:

(D2) $\quad T(b, f) \wedge$

$$
E(f) \rightarrow G(a, p)
$$

[ $b$ does $f$, and the occurrence of $f$ causes

$a$ to believe that $p$ ]

The opening of the window is an indicator in the sense of (D1). Causing an indicator such as this to occur is called 'indicator production'. In producing this indicator, the person who opened the window did not have to know that someone else was observing this action. Nor did s/he have to intend that observers draw conclusions from this action. Indicator production can be done unintentionally.

\section{Indicating}

Ronnie liked it when his classmates dropped by his house to play with him. When he was in his bedroom, he would open his window to let his friends know that he was there before they set foot on the property (see Plate 6).

By opening the window, Ronnie intended to cause his friends to assume that he was in his bedroom:

(D3) $T(b, f) \wedge$

$$
I(b, E(f) \rightarrow G(a, p))
$$

[ $b$ does $f$, and $b$ intends that

the occurrence of $f$ causes $a$ to believe that $p$ ]

In this case, opening the window is not just the unintentional production of an indicator. It is done with the intention that a recipient infer a certain message from it. We call a sign process of this sort 'indicating'. It is not necessary that the resulting message be true: there were times when Ronnie forgot to open his window although he was in his bedroom; there were other times when Ronnie's mother opened the bedroom window while Ronnie was gone. 


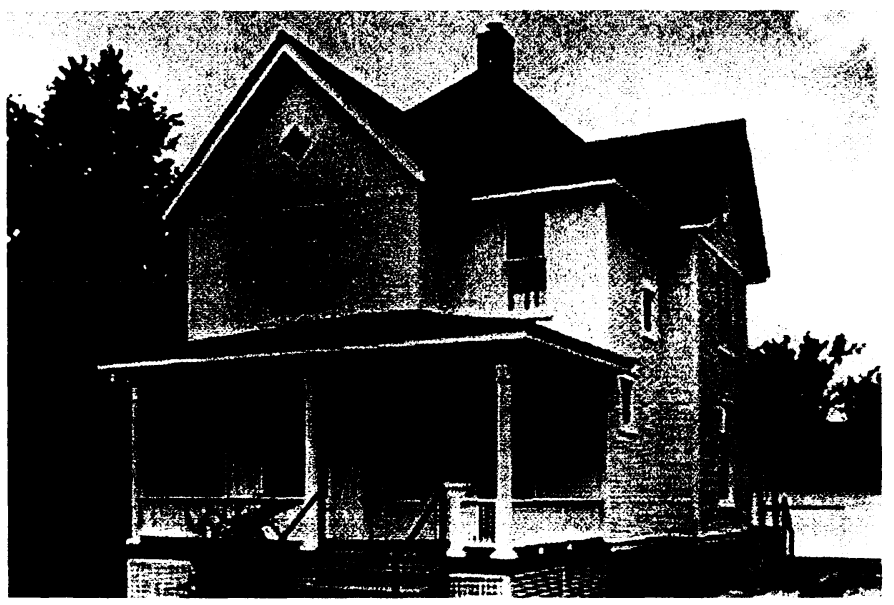

Plate 6. The Reagan family's house in Dixon (Reagan 1990: Fig. 2)

The expression

If a recipient interprets a circumstance as an indicator that its producer is in a certain state (i.e., a physical, emotional, mental, or social condition or disposition), we call the circumstance an 'expression' of that state. Ronnie's mother assigned him a flower bed in the yard to tend to. She interpreted the fact that the flower bed was always well watered as an expression of Ronnie's conscientiousness:

(D4) $\quad E(f) \rightarrow G(a, Z(b))$

[The occurrence of $f$ causes

$a$ to believe that $b$ is in the state $Z$ ]

That someone takes a circumstance to be an expression of its assumed producer's state necessitates neither that the circumstance was actually produced by the assumed person, nor that this person is in the assumed state.

\section{The expression production}

Even if Ronnie did regularly water the flower bed, he did not have to do it with the intention of causing his mother to regard him as conscientious. People can act conscientiously without thinking and without wanting to display it to others. In such cases, a person produces a circumstance 
which the others take to be an expression of his/her state, but s/he does this unintentionally:

(D5)

$$
\begin{aligned}
& T(b, f) \wedge \\
& E(f) \rightarrow G(a, Z(b)) \\
& {[b \text { does } f, \text { and the occurrence of } f \text { causes }} \\
& a \text { to believe that } b \text { is in the state } Z]
\end{aligned}
$$

We call making an expression in this manner 'expression production'.

\section{Expressing}

Ronnie liked being thought of as conscientious since it brought him praise and appreciation. Therefore, he actually did water the flowers with the intention that it cause his mother to believe that he was conscientious:

(D6)

$$
\begin{aligned}
& T(b, f) \wedge \\
& I(b, E(f) \rightarrow G(a, Z(b))) \\
& {[b \text { does } f, \text { and } b \text { intends that }} \\
& \text { the occurrence of } f \text { causes } a \text { to believe that } \\
& b \text { is in the state } Z]
\end{aligned}
$$

We call producing a circumstance with the intention of causing a recipient to assume that its producer is in a certain state 'expressing'. Through this action, the producer expresses his/her state.

Comparing these six types of sign-processes, D1 through D6, we realize that we are dealing with six different kinds of presentation:

In the rudimentary indicator process, D1, nobody has to present anything. Therefore, we can say, at best: 'the house presented itself to the recipient as being occupied'.

In the indicator production, D2, there is someone who presents a certain state of affairs through his/her actions: an inhabitant presents the house to the recipient as being occupied. But this can happen unintentionally.

Not until the act of indicating, D3, do we have presentation in the narrow sense. Ronnie intentionally presents his room to his friends as being occupied.

The verb 'to present' can be used in all three cases. Only in the case of D3, however, do we speak of 'presentation in the narrow sense', i.e., a process of producing a circumstance with the intention that others interpret it as an indicator of a certain state of affairs.

The sign processes D4 through D6 are special types of presentation in that their message concerns the state of a real or assumed indicator 
producer. In these cases, we speak of 'expression'. In the rudimentary expression process, D4, nobody has to express anything. We can say 'the flower bed expresses conscientiousness' without knowing if someone regularly tends to it or if this person wants the flower bed to express something of the kind.

In the expression production, D5, someone actually does express his/ her own state of being through actions: by watering the flower bed regularly, Ronnie expresses his conscientiousness. However, this can be done unintentionally.

It is not until the act of expressing, D6, that we have expression in the narrow sense: Ronnie waters the flowers regularly as an expression of his conscientiousness. We can speak of an 'expression in the narrow sense' when someone does something with the intention that others take it as an indicator of the state $s / h e$ is in.

\section{Types of self-presentation}

We can now ask which of the kinds of presentation discussed can be conceived as self-presentation. In answering this question, it makes sense to proceed from the expression production (D5) and the act of expressing (D6). Both cases have to do with presentation, and in both cases the presenter's state is presented. If we consider the 'self' notions which we discussed in the second section ('The types of selves'), then the following question becomes obvious: how does the indicator producer $b$ 's state $Z$, which is postulated in the expression processes, compare to the personality trait $P$, which we assumed in the analysis of the self? The answer is simple: a person's state can change, but a person's personality traits are considered to be permanent parts of his/her self. The appeal of a new activity may prompt Ronnie to water the flowers conscientiously for two weeks, after which he could lose interest. Conscientiousness is only regarded as one of Ronnie's personality traits if it persists over a longer period of time. (One would also expect that it not be limited to the act of watering the flowers.)

In this manner, we arrive at the assumption that self-presentation in the narrow sense takes place when a person does something with the intention that this action cause others to infer that a certain permanent feature (self-trait) is part of that person's self. This self-trait can be either: a personality trait as such, indicated by $P(b)$; or a self-conceived, otherconceived, self-wished, other-wished, etc. personality trait, indicated by $\ldots P(b)$ in the formula (SDM). 
$(\mathrm{SDM})$

$$
\begin{aligned}
& T(b, f) \wedge \\
& I(b, E(f) \rightarrow G(a, \ldots P(b))) \\
& {[b \text { does } f, \text { and } b \text { intends that }} \\
& \text { the occurrence of } f \text { causes } \\
& a \text { to believe that } \ldots b \text { is a } P]
\end{aligned}
$$

Self-presentation in the narrow sense has the structure given in (SDM); it is an act of expressing through which the presenter expresses a selftrait. Aside from the dots, the formula (SDM) differs from the formula for the act of expressing, D6, only in that $Z$ is replaced by $P$.

In the same way, self-presentation in a broader sense can be obtained from the formula for expression production, D5, by replacing $Z$ with $P$ : $\left(\mathrm{SDM}^{\prime}\right) \quad T(b, f) \wedge$

$$
\begin{aligned}
& E(f) \rightarrow G(a, \ldots P(b)) \\
& {[b \text { does } f, \text { and the occurrence of } f \text { causes }} \\
& a \text { to believe that } \ldots b \text { is a } P]
\end{aligned}
$$

Both self-presentation in the narrow and in the broader sense may result in the receiver's attributing a certain self-trait to the presenter. However, while this is the intended result of self-presentation in the narrow sense, self-presentation in the broader sense may have this consequence without the presenter intending it.

The two formulas, (SDM) and (SDM'), leave a great deal undetermined. For this reason, we call each a 'self-presentation matrix'. The dots in the matrix leave room for the structures which appear when we take into consideration the eight types of selves, S1 through S8, discussed in the second section ('The types of selves'). The formulas (S1) through (S8) define each type of self as a set $\{\ldots\}$ of self-traits which are either: personality traits as such, as in (S1); or self-conceived, selfwished, other-conceived, other-wished, etc. personality traits mediated by belief or intention, as in (S2), (S3), ... . To obtain self-presentation formulas that correspond to each type of self, we insert into the selfpresentation matrix the logical components of the set-theoretical formulas (S1) through (S8), i.e., those components to the right of the vertical slash. As a result, we obtain the following formulas.

\section{Self-presentation in the narrow sense (presentation of the personality)}

This formula characterizes the simplest case of self-presentation. Only $P(b)$ appears in the scope of $G(a, \ldots)$. The formula is obtained from the matrix formula (SDM) simply by omitting the dots (...):

(SD1) $\quad T(b, f) \wedge$

$$
I(b, E(f) \rightarrow G(a, P(b)))
$$


[ $b$ does $f$, and $b$ intends that

the occurrence of $f$ causes $a$ to believe that

$P(b)$ is true]

Self-presentation in the narrow sense consists in a person demonstrating directly to others a certain personality trait. After getting over some initial difficulties, young Reagan presented himself to his classmates as a football whiz by playing good football. If he did this unintentionally, then the formula is to be based on the matrix (SDM') rather than on (SDM).

\section{Self-concept presentation (presentation of the self-conceived self)}

In the corresponding formula, $G(b, P(b))$ appears in the scope of $G(a, \ldots)$. The formula is obtained by replacing the dots in the matrix formula (SDM) with $G(b$, and suitably closing the parenthesis:

(SD2) $\quad T(b, f) \wedge$

$I(b, E(f) \rightarrow G(a, G(b, P(b))))$

[ $b$ does $f$, and $b$ intends that.

the occurrence of $f$ causes $a$ to believe that

$b$ thinks that $P(b)$ is true]

The presentation of a person's self-conceived self consists in a person behaviorally expressing to others his/her opinion of him/herself regarding a possible personality trait. Through his rugged performance during the try-out for the class team, Ronnie presented himself as someone who considers himself to be a pro at football. If he did this unintentionally, then $\left(\mathrm{SDM}^{\prime}\right)$ must be used as the basis of the formula rather than (SDM).

\section{Image presentation (presentation of the other-conceived self)}

In the corresponding formula, $G(a, P(b))$ appears in the scope of $G(a, \ldots)$. The formula is based on the matrix formula (SDM) and is arrived at by replacing the dots in (SDM) with $G(a$, and suitably closing the parenthesis:

(SD3) $\quad T(b, f) \wedge$

$I(b, E(f) \rightarrow G(a, G(a, P(b))))$

[ $b$ does $f$, and $b$ intends that

the occurrence of $f$ causes $a$ to believe that

$a$ believes that $P(b)$ is true] 
The presentation of a person's other-conceived self consists in a person $b$ calling through his/her behavior other people's attention to their own opinion of $b$. By running to the board whenever the teacher wanted something written nicely, Ronnie presented himself to his classmates as a 'fine writer on active duty', i.e., as one whom the others deemed a fine writer. If he did this unintentionally, then $\left(\mathrm{SMD}^{\prime}\right)$ must be used as the basis for the formula.

Self-wish presentation (presentation of the self-intended self)

In this formula, $I(b, P(b))$ appears in the scope of $G(a, \ldots)$. The formula is obtained by replacing the dots in the matrix formula (SDM) with $I(b$, and suitably closing the parenthesis:

(SD4) $\quad T(b, f) \wedge$

$I(b, E(f) \rightarrow G(a, I(b, P(b))))$

[ $b$ does $f$, and $b$ intends that

the occurrence of $f$ causes $a$ to believe that

$b$ wants $P(b)$ to be true]

The presentation of a person's self-intended self consists in the person behaviorally expressing to others that $\mathrm{s} / \mathrm{he}$ is striving to acquire a certain personality trait. By practicing diligently, Ronnie presented himself to his parents as one who would like to be a good football player. If this outcome was unintentional, then (SDM') must be used as the basis for the formula.

\section{Other-wish presentation (presentation of the other-intended self)}

In this formula, $I(a, P(b))$ appears in the scope of $G(a, \ldots)$. It is arrived at by replacing the dots in the matrix formula (SDM) with $I(a$, and suitably closing the parenthesis:

(SD5) $\quad T(b, f) \wedge$

$I(b, E(f) \rightarrow G(a, I(a, P(b))))$

[ $b$ does $f$, and $b$ intends that

the occurrence of $f$ causes $a$ to believe that

$a$ wants $P(b)$ to be true]

The presentation of a person's other-intended self consists in a person $b$ pointing out to other people his/her own desire that $b$ possess a certain personality trait. Ronnie sometimes misbehaved during card games. In doing so, he presented himself to his playmates as someone who should play fair, i.e., as someone of whom the playmates demanded fairness. 
If he did this unintentionally, then the formula must be based on (SDM') rather than on (SDM).

Image-concept presentation (presentation of the self-conceived other-conceived self)

In the corresponding formula, $G(b, G(a, P(b)))$ appears in the scope of $G(a, \ldots)$. The formula is obtained by replacing the dots in the matrix formula (SDM) with $G(b, G(a$, and suitably closing the parenthesis:

(SD6) $\quad T(b, f) \wedge$

$I(b, E(f) \rightarrow G(a, G(b, G(a, P(b)))))$

[ $b$ does $f$, and $b$ intends that

the occurrence of $f$ causes $a$ to believe that

$b$ believes that $a$ believes that $P(b)$ is true]

The presentation of a person's self-conceived other-conceived self consists in a person behaviorally making clear to others that $\mathrm{s} / \mathrm{he}$ believes that they have a certain opinion of him/her. Ronnie occasionally feigned modesty when cast for the main role of a play. In doing so, he presented himself as someone who believed that the others considered him a top actor, one who could, therefore, afford to simulate being a modest person. If this result was unintentional, then (SDM') must replace (SDM) as the basis for the formula.

\section{Image-wish presentation (presentation of the self-intended} other-conceived self)

In the corresponding formula, $I(b, G(a, P(b)))$ appears in the scope of $G(a, \ldots)$. It is arrived at by replacing the dots in the matrix formula (SDM) with $I(b, G(a$, and suitably closing the parenthesis:

(SD7) $\quad T(b, f) \wedge$

$$
I(b, E(f) \rightarrow G(a, I(b, G(a, P(b)))))
$$

[ $b$ does $f$, and $b$ intends that

the occurrence of $f$ causes $a$ to believe that

$b$ wants $a$ to believe that $P(b)$ is true]

The presentation of a person's self-intended other-conceived self consists in a person making clear to others through behavior that $\mathrm{s} /$ he would like it if they had a certain opinion of him/her. Every chance he got, Ronnie invited his friends to a self-prepared meal. In doing so, he presented himself as someone who would like to have the reputation of being a good cook. If he did this unintentionally, then the formula must be based on $\left(\mathrm{SDM}^{\prime}\right)$ rather than on $(\mathrm{SDM})$. 
Image-wish-image presentation (presentation of the other-conceived self-intended other-conceived self)

In the corresponding formula, $G(a, I(b, G(a, P(b))))$ appears in the scope of $G(a, \ldots)$. It is obtained by replacing the dots in the matrix formula (SDM) with $G(a, I(b, G(a$, and suitably closing the parenthesis:

(SD8)

$$
\begin{aligned}
& T(b, f) \wedge \\
& I(b, E(f) \rightarrow G(a, G(a, I(b, G(a, P(b)))))) \\
& {[b \text { does } f, \text { and } b \text { intends that }} \\
& \text { the occurrence of } f \text { causes } a \text { to believe that } \\
& a \text { believes that } b \text { wants } a \text { to believe that } \\
& P(b) \text { is true] }
\end{aligned}
$$

The presentation of a person's other-conceived self-intended otherconceived self consists in a person behaviorally pointing out to others that they think that $\mathrm{s} / \mathrm{he}$ wants them to have a certain opinion of him/ her. For a while, Ronnie overdid the exhibition of his cooking talents. This made the others aware not only that he wanted to be regarded as a good cook, but also that they themselves believed that he wanted to be regarded as such. That is, he rubbed their noses in the fact that they considered him to be a show-off. This led to much teasing of him on their part. If Ronnie behaved in this manner unintentionally, then $\left(\mathrm{SMD}^{\prime}\right)$ must serve as the basis for the formula rather than (SDM).

The formulas (SD1) through (SD8) describe common types of selfpresentation. Further self-presentation formulas can be constructed by making other types of selves (see Fig. 1) the object of expressing.

\section{Self-development through illusion and simulation}

As the previous section shows, the structures of self-presentation can be quite complex. Important, however, is the observation that they are all made up of the same components: personality traits and doing, intending, believing, and causing. As mentioned in the discussion of the self-conceived other-conceived self (in the second section), a person need not actually have the personality trait that $\mathrm{s} / \mathrm{he}$ believes $\mathrm{s} /$ he possesses (self-conceived self), or desires to possess (self-intended self), or that others believe (other-conceived self) or desire (other-intended self) him/ her to possess. If the person does not have this personality trait, i.e., if $\neg P(b)$ is true, then we are dealing with a virtual personality trait.

The same holds for the others' assumptions of and wishes for virtual personality traits: a person can believe (self-conceived other-conceived self) or desire (self-intended other-conceived self) that the others have 
a certain opinion of him/her; a person can also believe (self-conceived other-intended self) or desire (self-intended other-intended self) that the others want him/her to possess a certain personality trait. However, it can at the same time be true that the others do not actually believe or wish these things. In cases such as this, we are dealing with virtual other-concepts and other-wishes.

This is also true for the person's assumptions of and wishes for virtual personality traits: the others can believe (other-conceived selfconceived self) or wish (other-intended other-conceived self) that a person believes that $\mathrm{s} / \mathrm{he}$ possesses a certain personality trait; the others can also believe (other-conceived self-intended self) or wish (other-intended self-intended self) that a person wants to possess a certain personality trait. All of this can be true, however, even if the person does not actually assume or desire to possess this trait. In this case, we are dealing with virtual self-concepts and self-wishes.

We speak of 'illusion' when one assumes the existence of personality traits, self-concepts, self-wishes, other-concepts, or other-wishes when in fact they are only virtual. Similarly, we speak of 'simulation' when one presents oneself as possessing personality traits, self-concepts, selfwishes, other-concepts, or other-wishes although they are only virtual.

Thus, here as well as elsewhere, simulation consists in the creation of an illusion. The question now arises as to what role virtual personality traits, self-concepts, self-wishes, other-concepts, or other-wishes play in self-presentation. The key question is: is self-presentation possible without illusion and simulation?

This question is particularly relevant in relation to the process by which a child (like young Reagan) develops his or her self. If we orient ourselves on the structure of the stratified total-self (see Fig. 1), then it would seem obvious that: Ronnie began by developing certain personality traits, $P(b)$; then he developed the respective self-concept, $G(b, P(b))$; finally, after interacting with others, he developed the corresponding self-concept of their other-concept of his personality, $G(b, G(a, P(b)))$, etc. Given this course of development, the personality trait would exist first and would then be perceived with a continually growing awareness. The development would start with the self in the narrow sense at the level of reflection RS0 and would slowly climb to higher levels of reflection in concurrence with the traits on the level RS0.

However, self-development does not always follow this course. This becomes quite clear when we consider the self-wishes and the otherwishes: these tend to occur, when the respective personality trait does not (yet) exist: $\neg P(b)$. Therefore, there must be constellations in which the personality trait concerned does not exist at the bottom reflection 
level (RS0) and at the same time is attributed at higher reflection levels, i.e., $I(b, P(b))$ as with self-wishes or $I(a, P(b))$ as with other-wishes. This holds true for physical as well as for mental personality traits: a person who does not have blond hair and blue eyes could want to be blond-haired and blue-eyed, and a person who is not good at mathematics could want to be.

Now, missing physical personality traits, such as blond hair and blue eyes, cannot be called into existence by self-wishes or other-wishes. It is a different matter, however, with dispositions such as competence in mathematics and other mental personality traits. Here, selfwishes, other-wishes, and other-concepts are determining factors in the self-development.

Young Ronnie's (see Plate 7) experiences confirm this impressively:

- Ronnie, who until then had only occasionally written finely, began to be a fine writer when the teacher formed a corresponding other-concept and confronted Ronnie with this. Ronnie's assumption that the teacher considered him a fine writer (and also the advantages to be gained by being one) prompted him to become one:

(9) $\quad G(b, G(a, P(b))) \rightarrow P(b)$

[that $b$ believes that $a$ believes that $b$ is a $P$

causes $b$ to be a $P$ ]

- Ronnie, who until then was a poor football player, was angry that he was left on the side-lines when it came time to select the players for the class team. He wanted to be considered a good football player because this would, in general, give him clout with his classmates. His desire that the others consider him a good player caused him gradually to become one:

$$
I(b, G(a, P(b))) \rightarrow P(b)
$$

[that $b$ wants $a$ to believe that $b$ is a $P$

causes $b$ to be a $P$ ]

- Ronnie, who until then had only occasionally memorized and recited texts, began developing into a good amateur actor when his mother asked him to perform for her recital club. Ronnie's assumption that his mother wanted him to be a good amateur actor (as well as the applause he received from the others) caused Ronnie to become one:

(11) $\quad G(b, I(a, P(b))) \rightarrow P(b)$

[that $b$ believes that $a$ wants $b$ to be a $P$

causes $b$ to be a $P$ ]

We can note the following: Manifest physical traits develop, to a great extent, automatically; one has to learn to accept them. Dispositional mental traits, however, do not develop on their own. The individual develops these mental traits once they have been introduced on a higher level of reflection and have become desirable. Mental personality 


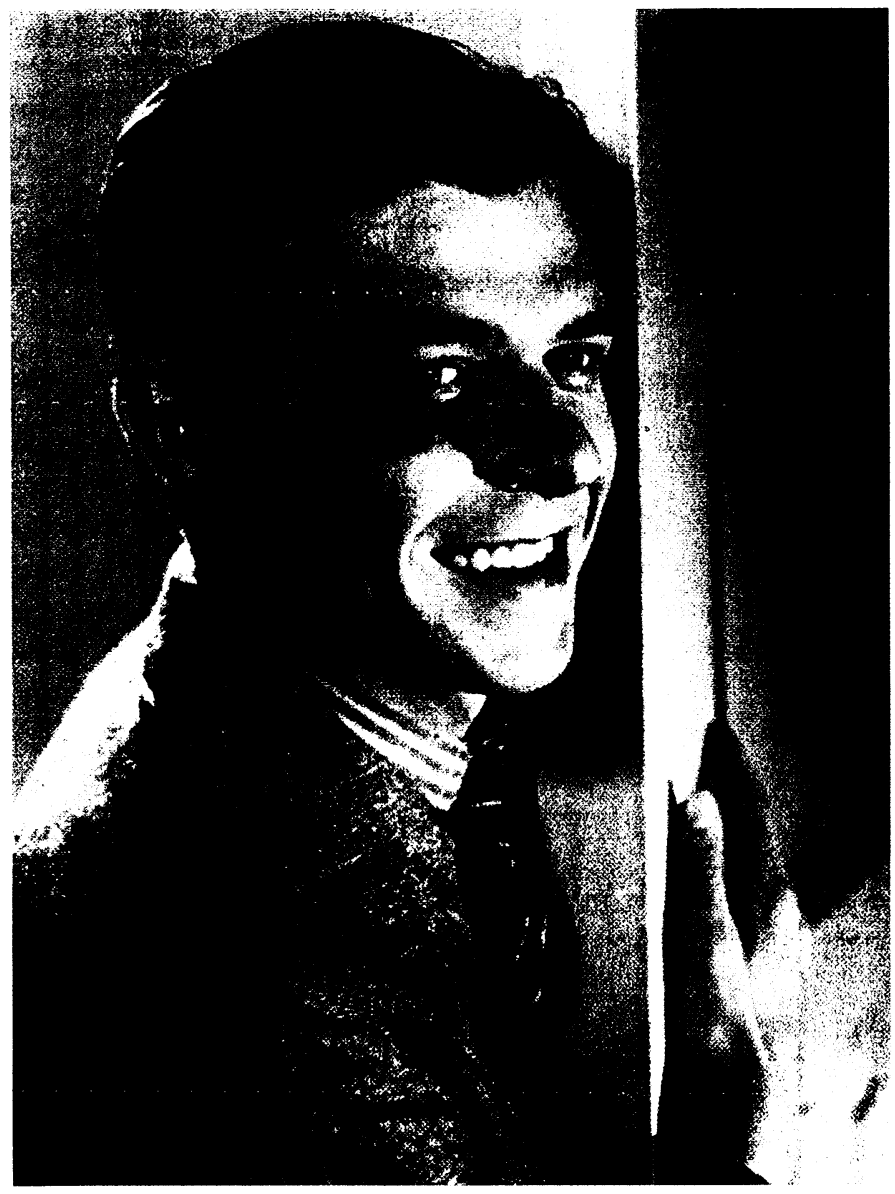

Plate 7. Reagan at the age of 27 (Friedman 1986: 33)

traits are to a great extent dependent upon other-concepts, self-wishes, and other-wishes. This means that they are socially controlled.

A second observation can be made as we consider the formulas (9) through (11). A transition takes place as the abilities to write finely, play football, and act are developed: the self of a higher level of reflection becomes a self of a lower level of reflection. The level of reflection is reduced by two levels from RS2 to RS0: because Ronnie believes that the teacher believes that Ronnie is a fine writer, Ronnie becomes a fine writer; because Ronnie wants the others to believe that he is a good football player, he becomes a good football player; because Ronnie 
believes that his mother wants him to be a good amateur actor, Ronnie becomes a good amateur actor.

The adoption of personality traits by means of level reduction serves to eliminate inconsistencies within and contradictions between the levels of the total-self. At first, $\neg P(b)$ occurs at the lowest level of reflection and ...P $P(b)$ occurs at the higher levels (where $P(b)$ is embedded in sequences of the operators $G(\ldots, \ldots)$ or $I(\ldots, \ldots))$. By developing the personality trait $P(b)$, the person establishes inter-level consistency throughout his/her total-self.

A prime example of this type of situation and how it can be mastered is offered in the second section ('The image-concept'): young Reagan was actually an average football player, but he considered himself to be a football genius; at the same time, he thought that his teammates regarded him as a failure, whereas they only deemed him average. To free himself from this painful situation, Ronnie practiced so much that he actually became a good football player. This gave the others reason to regard him as such, and Ronnie no longer had to believe that their opinion of him differed from his own. As a result, Ronnie was not just virtually a good football player by virtue of his self-assessment, but was a good football player on all the levels of reflection involved.

At least with regard to the mental personality traits, it follows that a person's self is not an unalterable given. It is socially formed and is developed proceeding from the virtual personality traits represented at higher levels of reflection, i.e., by means of illusion and simulation. Ronnie was not yet a fine writer when the teacher said to him, 'you are a fine writer': $G(a, P(b))$ and $\neg P(b)$. However, his teacher saying this to him caused Ronnie to become one; see formula (9). Nor was Ronnie a good football player when he at first acted like one and wanted his teammates to regard him as one: $I(b, G(a, P(b)))$ and $\neg P(b)$. However, by virtue of his self-wish he became a good football player; see formula (10). On the day that Ronnie's mother encouraged him to perform as an amateur actor, Ronnie was not one yet: $I(b, P(b))$ and $\neg P(b)$. However, due to this otherwish, Ronnie became an amateur actor; see formula (11). Illusion was at play every time, and simulation, quite often. The personality traits existed virtually before becoming reality.

This raises the issue of how reality can originate from simulation. To answer this question, we must take into account the dialectic of the individual act and the permanent feature, which I touched on earlier in the second section (first part). Let us consider this further, using an example which was essential to Reagan's career transition from actor to politician. In order to be regarded as a good politician, Reagan had to avoid making the impression that he was simply reciting speeches 
written by other people (see Ripper 1998: 111 and 115). He had to prove his autonomy to the citizens by repeatedly voicing his unswerving convictions in a spontaneous manner. How can people learn to be spontaneous? They have to try to appear spontaneous. Reagan acquired a supply of stories and jokes and told these whenever it was appropriate. He played a person who improvised well. Every successful improvisation strengthened his reputation as an improviser. Since playing the role of an improviser consisted in having to constantly improvise anew, Reagan got so much practice at improvising that he actually became a good improviser. His acting could no longer be distinguished from reality. By means of frequent simulation, Reagan became the person he was simulating. His self was not the starting point but rather the result of self-presentation; he developed his self through self-presentation. It is only in the light of this that we can understand remarks about Reagan such as those made by Peggy Noonan, Reagan's speech writer of many years (Noonan 1990: 158): 'He really always played himself ... . That's why he seemed both phony and authentic. Because he was. He was really acting but the part he played was Ronald Reagan'. He appeared phony because he was practicing selfpresentation; he seemed authentic because his means of presentation were manifestations of the person he portrayed. (cf. Morris 1999; for a discussion of the problems which develop when an actual actor/actress is mistaken for the politician s/he portrays, see Posner 1994.)

To demonstrate that this fascinating self-development process can be fully described by means of our technical concepts, let us represent it by using the corresponding formulas:

1. The person $b$ wants the others $a$ to attribute to him/her a certain self-trait $F$ :

(i) $\quad I(b, G(a, F(b)))$

[ $b$ wants $a$ to believe that $b$ is an $F$ ]

2. In $b$ 's opinion, this image-wish (self-intended other-conceived self) can be realized if $b$, in all relevant situations $t$, acts like someone who is an $F$, i.e., who does $f$ :

(ii) $\quad G\left(b, \forall t T_{t}(b, f) \rightarrow G(a, F(b))\right)$

[ $b$ believes that if it is true for all $t$ that

$b$ does $f$ in $t$ then this will cause

$a$ to believe that $b$ is an $F$ ]

3. Person $b$ 's wish that he appear to the others as an $F(\mathrm{i})$ and his belief that this will happen if he does $f$ in all relevant situations $t$ (ii) cause $b$ to do $f$ in all relevant situations:

(iii) $\forall t T_{t}(b, f)$

[it is true for all situations $t$ that

$b$ does $f$ in $t$ ] 
4. Now it is an analytically true statement that one who does $f$ in all relevant situations $t$ is an $f$-doer, i.e., is an $F$ :

(iv) $\forall x \forall t\left(T_{t}(x, f) \supset F(x)\right)$

[it is true for all people $x$ and all situations $t$ that

if $x$ does $f$ in $t$, then $x$ is an $F$ ]

5. By substituting $b$ for $x$ in (iv) and by modus ponens using (iii), we derive from (iv):

(v) $\quad F(b)$

[b is an $F$ ]

6. In trying to convince $a$ that $b$ is an $F$ by means of $\operatorname{doing} f, b$ actually became an $F$. The only requirement was that there were enough relevant situations in which $b$ could do $f$. The generalized summary is as follows:

(vi)

$$
\begin{aligned}
& \forall x \forall t\left(T_{t}(x, f) \wedge I\left(x, T_{t}(x, f) \rightarrow G(a, F(x))\right)\right. \\
& \rightarrow F(x))
\end{aligned}
$$

[it is true for all people $x$ and situations $t$ that

if $x$ does $f$ in $t$ because $x$ wants

doing $f$ in $t$ to cause $a$ to believe that $x$ is an $F$ then this causes $x$ to be an $F$ ]

The formula (vi) describes what I propose to call the 'Reagan Effect'. It shows the logical structure in which level reduction from ...I( $x, \ldots G(a$, $F(x)))$ to $F(x)$ takes place.

For pairs of acts $f$ and personality traits $F$, for example,

\begin{tabular}{ll}
\hline \multicolumn{1}{c}{$f$} & \multicolumn{1}{c}{$F$} \\
\hline 'writing (finely)' & '(fine) writer' \\
'swimming (well)' & '(good) swimmer' \\
'playing football (well)' & '(good) football player' \\
'losing fairly' & 'fair person' \\
'cooking well' & 'good cook' \\
'working conscientiously' & 'conscientious worker' \\
'acting (well)' & '(good) actor' \\
'improvising (well)' & '(good) improviser' \\
'acting intelligent' & 'intelligent person' \\
'presiding' & 'President' \\
\multicolumn{1}{c}{ ( } & \multicolumn{1}{c}{ : } \\
\hline
\end{tabular}

concluding the presence of a self-trait on the basis of a few occurrences of the corresponding act is always justified under the described conditions. 
Ultimately, the Reagan Effect explains the fact that, by constantly presenting a certain self, one becomes this self. This is only possible due to the fact that our selves are not pre-defined but rather must be developed.

The Reagan Effect boils down to the fact that an aspired reality can be brought about by the mental anticipation of it. It is a special case of the self-fulfilling prophecy (see Merton 1948; Rosenthal 1968; Ludwig 1991) and is, therefore, to be put in the same category as these other effects: the Rosenthal Effect, which consists in the researcher's expectations influencing the test person's behavior; the Pygmalion Effect, by which the teacher's expectations affect the student's achievement (see Rosenthal and Jacobson 1968); the Messiah Effect, by which propagating a prophecy influences the development of the prophecy's object (see Eden 1986); the Galatea Effect, by which fearing an event makes the occurrence of this event more probable (see Rosenthal 1975); and the placebo effect, which consists in the belief in an effect evoking that effect (see Kirsch 1985). In contrast to these types of self-fulfilling prophecies, however, the Reagan Effect is based on a logically transparent and unchanging mechanism: the creation of a personality trait through the exhibition of its manifestation.

The Reagan Effect results in the development of dispositional selftraits. It cannot be used to produce manifest physical traits; the human being's possession of two arms, two legs, two eyes, two ears, one nose, and one mouth are out of its range. But the traits pertaining to the way in which the body parts move, whether

- awkwardly or smoothly,

- sedately or swiftly

and, most definitely, the traits involving more complex behavioral patterns, whether

- pedantic or flexible,

- reliable or unreliable,

- obliging or unwieldy,

- friendly or stubborn,

- finicky or easily pleased,

- honest or insidious,

can be acquired by displaying their manifestations. At first, the display might not be a completely successful one since the displayed trait is in its earliest stage of development. The presentation takes place before that which is presented exists. Through presentation, however, the presenter gets enough practice that, eventually, s/he has not only mastered the art of presentation but also that which $\mathrm{s} / \mathrm{he}$ is presenting. 


\section{The computer as a self-presenter}

Can the results of our analysis of human self-development be applied to artificial cognitive systems? Can computers develop a self in the same manner?

With computers, too, it is necessary to differentiate between manifest physical properties and behavioral dispositions. In the same way that a human is supplied with arms, legs, eyes, ears, a nose, and a mouth, the present-day computer has input devices (keyboard, joystick, mouse, or scanner), output devices (monitor, printer, or plotter), a memory (hard drive and main memory) and a processor. Just as the arms and legs can be thin or fat and long or short, and the ears, nose and mouth can be big or small and delicate or gross, so can the computer-design be clumsy or elegant and angular or streamlined. Just as human beings can have one of several possible skin tones (light, dark), hair-colors (blond, brown, black), and eye-colors (blue, gray, brown), so can a computer have: a beige, gray or black housing; a reflecting or non-reflecting screen; a black-and-white or color monitor. Characteristic traits such as these are fixed at the time of birth or fabrication. Afterwards, they usually remain unchanged unless damage or injury occurs, as was the case with Drake McHugh. For both human beings and computers, the distribution of the traits among the total population is determined by the public (by those active in the marriage market or in the computer market).

Human beings develop behavioral dispositions, for example, to eat a little or a lot, to speak slowly or quickly, or to read often or rarely. Computers also show behavioral patterns: the keys can be springy or stiff, and hardly or highly delayed; the processor can be slow or fast; the printer can function reliably or faultily.

Of greater interest in this context are, however, the dispositions which the computer-users attribute to their computers (see Leu 1993): They regard them as

- pedantic or flexible,

- reliable or unreliable,

- obliging or unwieldy,

- friendly or stubborn,

- finicky or easily pleased,

- honest or insidious.

Each of these assessments is based on behavior. They interpret the experiences gained on many occasions (see Fig. 2).

For computers and human beings, the manifest material traits and behavioral dispositions are both included in what we have called 'self in the narrow sense': $\{P \mid P(b)\}$. The material traits and some of the 


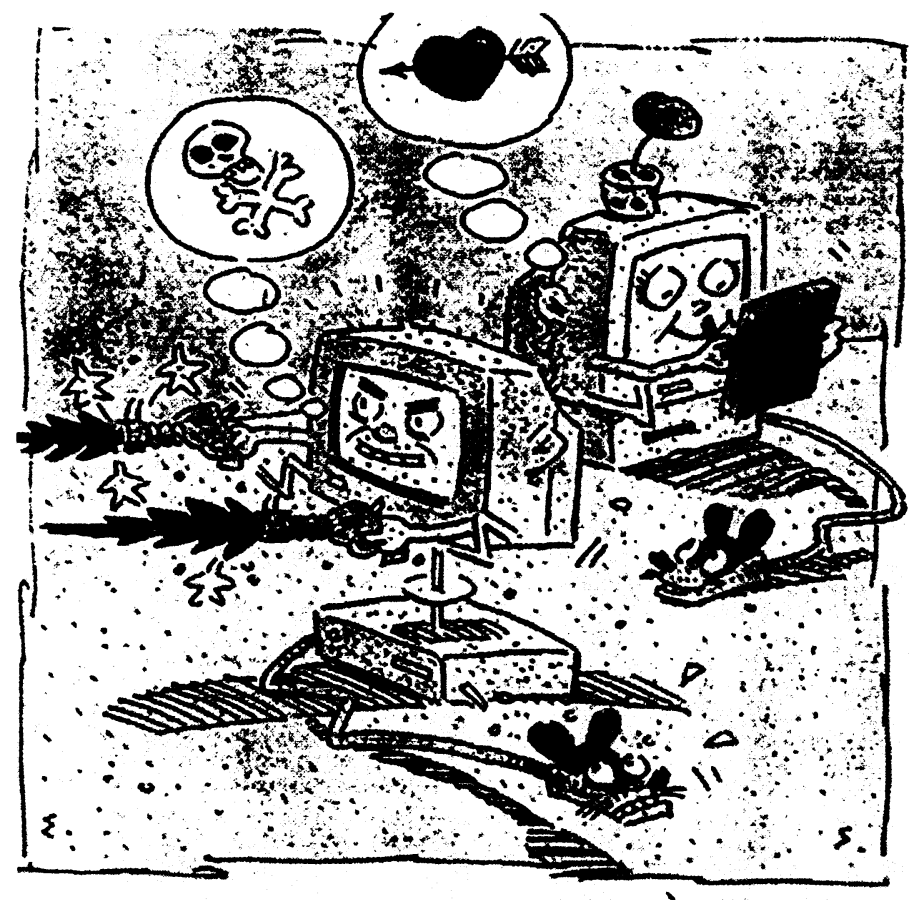

Figure 2. The user creates a PC in his/her own likeness (drawing by Elwood H. Smith, in Kantrowitz 1994: 51)

elementary dispositional characteristics belong to the options which were determined at the factory and can, therefore, hardly be changed. The user (and the computer) simply have to accept them.

But what about dispositions such as being pedantic vs. flexible, reliable vs. unreliable, obliging vs. unwieldy, friendly vs. stubborn, finicky vs. easily pleased, honest vs. insidious? If the user attributes these to the computer, then these dispositions belong to the computer's other-conceived self: $\{P \mid G(a, P(b))\}$.

In cases in which the user empathizes strongly with the computer, it is possible that, in addition to these selves on the reflection levels 0 and 1 , a third level is reached: users who, despite all attempts, are unable to find a file on their computer might accuse the computer of trying to hide the file. They curse and call their computer names. Then later, they might forget to save a different file before deleting it. In their despair, they blame the computer for losing the file, saying that the computer was getting even for being cursed at earlier. 
The computer industry tries to counter such user disruptions of the work atmosphere with software which supplies the computer with a tension-reducing human demeanor. After turning on the computer, the computer visually and audibly greets the user: 'Hi Joe, how are you today?' Having made a mistake, the user is politely made aware that s/he has not followed the rules: 'This was a mistake. Please try again'. Having accomplished a difficult task, the user is rewarded with a praising remark on the monitor: 'Well done!'

All of these measures facilitate the user's impression that the computer is a communication partner (or a playmate). The technical literature differentiates between user conduct in accordance with the partner metaphor (Maaß 1984) and user conduct in accordance with the instrument or media metaphor (Andersen 1990). The majority of authors object to the anthropomorphization of the computer, arguing that: this is the result of a misunderstanding; face-to-screen interaction with the computer must not be interpreted as face-to-face communication with a human partner; the computer is unable to communicate in the strict sense since it lacks characteristics such as normativeness, affectivity, contextuality, historicity, sociality, personality, freedom, and consciousness (see Debatin 1994: 14); the computer can at the most be attributed a virtual self; wanting to communicate with this virtual self is an illusion.

In the light of this controversy, let us summarize the facts once again and then determine under which conditions the virtual computer-self could develop into a real self.

1. Due to its manifest physical features, it is unavoidable that every computer has a self in the narrow sense:

(S1) $\quad\{P \mid P(b)\}$

For example, it is angular, streamlined, gray, non-reflecting, springy, hardly delayed, multi-colored and super-fast.

2. Through user attribution, the computer acquires an otherconceived self:

(S3) $\quad\{P \mid G(a, P(b))\}$

For example, the computer is considered pedantic, reliable, unwieldy, stubborn, and finicky.

3. In the same manner, the computer is given an other-intended self: (S5) $\quad\{P \mid I(a, P(b))\}$

Users are often disappointed with the operating results and transfer this disappointment to the computer. They want the computer to become less unwieldy, stubborn, and finicky and become more obliging, user friendly, and easily pleased.

4. The more involved computer freaks attribute a self-conceived self to the computer in that they assume that the computer considers 
itself the better calculator, chess player, pilot, etc. In this manner, the computer receives an other-conceived self-conceived self:

(S9) $\quad\{P \mid G(a, G(b, P(b)))\}$

The dynamics of the user-computer interaction entail that the features, $P(b)$, attributed here differ from those attributed to the computer in the other-intended self.

5. Computer freaks also assume that their computers have their own intentions, which gives the computer an other-conceived self-intended self: (S10) $\quad\{P \mid G(a, I(b, P(b)))\}$

After the tenth attempt to retrieve a specific file from the computer, an imaginative user can hardly avoid thinking that the computer senses a certain satisfaction at its anal-retentive character and intends to hold onto the text forever.

6. Finally, we have to reckon with an other-intended self-conceived self: (S11) $\quad\{P \mid I(a, G(b, P(b)))\}$

Users who cannot get the better of their computer or its game program wish that it would regard itself as being less perfect and act a little more human.

7. As in romantic human relationships, computer freaks are often motivated to demand that their partner, the computer, try harder to meet their needs. They want the computer to be capable of self-wishes, and they believe that this would be the first step towards its improvement.

(S12) $\quad\{P \mid I(a, I(b, P(b)))\}$

8. Finally, in more complicated situations in which the user has verbally abused the computer and afterwards feels himself/herself punished by the computer for doing so, s/he will think: 'You want me to consider you more honest, huh? Then start acting like it!' In this case, we are dealing with an other-conceived self-intended other-conceived self:

(S8) $\quad\{P \mid G(a, I(b, G(a, P(b))))\}$

The sub-selves in this list are located on the reflection levels RS0 through RS3 (see Fig. 1). What is still needed to complete the total-self on all levels of reflection are the following.

9. The computer's self-conceived self (reflection level RS1):

(S2) $\quad\{P \mid G(b, P(b))\}$

This self would be involved if the computer were able to regard itself, for example, as pedantic, reliable, obliging, friendly, finicky, and honest (as users sometimes assume (S9) or wish (S11) to be possible).

10. The computer's self-intended self (reflection level RS1):

(S4)

$\{P \mid I(b, P(b))\}$

This self would be involved if the computer could intend, for example, to be less pedantic, unwieldy, and stubborn (as users sometimes assume (S10) or wish (S12) to be possible). 
11. The computer's self-conceived other-conceived self (reflection level RS2):

(S6) $\quad\{P \mid G(b, G(a, P(b)))\}$

This self would be involved if the computer could believe that the user regards it, for example, as unwieldy, stubborn, and insidious, or as obliging, user friendly, and honest.

12. The computer's self-intended other-conceived self (reflection level RS2):

(S7) $\quad\{P \mid I(b, G(a, P(b)))\}$

This self would be involved if the computer could want the user to regard it, for example, as less unwieldy, stubborn, and insidious, i.e., as obliging, user-friendly, and honest (the user presumes this type of computer-wish in S8).

13. The computer's self-conceived other-intended self (reflection level RS2):

(S13) $\quad\{P \mid G(b, I(a, P(b)))\}$

This self would be involved if the computer could have an idea of the user's needs and could believe that the user wants it to be obliging, user-friendly, and honest.

14. The computer's self-intended other-intended self (reflection level RS2):

(S14) $\quad\{P \mid I(b, I(a, P(b)))\}$

This self would be involved if the computer were able to wish for the user's wishes. For example, the computer could want the user to want it to be more flexible, to operate quicker, and to have a larger memory.

In accordance with the stratified total-self shown in Figure 1, further computer sub-selves can be postulated at the higher levels of reflection; discussing them, however, would not add anything new to our current train of thought.

If we analyze the RS1 and RS2 sub-selves that are not part of today's interaction with computers according to the partner metaphor, we realize that they all contain more or less complex feature attributions which are embedded either in $G(b, \ldots)$ or in $I(b, \ldots)$. Those who want to provide their computers with these sub-selves must, therefore, enable them to believe and intend things.

Let it be noted, however, that it would be a wrong solution to program the computer to believe and intend certain things. Such an engineering solution would deny the computer the ability to adapt itself to each user and, based on the user's individual operating conduct, to develop a concept of his/her habits, assessments, and wishes. The computer must only be programmed to be able to believe and intend as such. It must be so 
equipped that it becomes able to produce internal representations of its own traits and those of others (that is, 'to believe') and to evaluate these with regard to its own preferences (that is, 'to intend').

Being so equipped, the computer would be able to develop the heretofore missing half of its total-self. The self-development process could take place as with young Reagan, proceeding from the other-concepts, self-wishes, and other-wishes (see the formulas [9] through [11] in the fifth section - 'Self-development through illusion and simulation'). Would it not be helpful to own a PC that, just because it believes that user $a_{1}$ considers it to be flexible, tries to justify this assessment by choosing the most effective shortcuts in all operation sequences? Or a PC that, because it believes that user $a_{2}$ wants it to be pedantic, reviews each step of an operation sequence with him/her explicitly? Or a PC that independently looks for an apparently lost file by trying to guess the correct code words based on the user's failed attempts? Or a PC that corrects spelling and punctuation errors on its own because it thinks they do not correspond to the user's writing intentions? Or a PC that rounds out its user's incomplete commands and then executes them? Or a PC that, after the user's nth failed attempt to formulate a text, uses its own formulation program to produce a new text variation that better corresponds to the assumed intentions of the user?

All of these possibilities are opened up if the computer is given the ability to believe and to intend. The Reagan Effect takes care of the rest.

As a cognitive system that can believe and intend things, the computer could use its experiences of working with the user to independently develop itself and (re-)organize its technical capabilities. The computer is not given its self-conceived self and its self-intended self, but rather has to develop these based on the other-conceived self and the otherintended self with which the user confronts it. In this manner, the computer is able to expand and change its self in the narrow sense. This takes place through the level reduction of attributed traits. Attribution through others motivates self-presentation, and this results in self-development.

Such a cognitive system is capable of each type of self-presentation discussed in the third and fourth sections since these are simply various constellations of believing, intending, and causing trait attribution. The higher the level of reflection reached by the system in its work with the user, the more the computer will resemble the user. It will automatically develop from a mere instrument to a thinking partner, from an anonymous configuration of data to a collaborator capable of adaptation. Discussions about the metaphorics of these descriptions will become unnecessary. 
An artificial cognitive system with the ability to think and to intend things will not only possess the unavoidable self in the narrow sense, which the psychoanalyst Khan attributed to his colleague Winnicott. It will also possess a total-self that is unyielding insofar as it strives for an inner consistency between its sub-selves on the higher and lower levels of reflection. And its total-self will be invulnerable to the degree to which this striving for inter-level consistency enables it to remove contradictions resulting from physical damage. This will be accomplished either by dispensing with self-traits on the lowest level or by redeveloping the lost traits based on the mechanism of level reduction. Each partner interacting with this cognitive system will be able to form his/her own picture of it; although the computer will not 'try to force its own way of being' on its partners, it will still always 'unavoidably be itself'.

These promising characteristics of the artificial cognitive systems concerned should make it worthwhile to devote ourselves more seriously than before to the semantic and pragmatic research of that which makes them possible: believing and intending.

\section{References}

Andersen, Peter B. (1990). A Theory of Computer Semiotics. Cambridge, UK: Cambridge University Press.

Burns, Robert B. (1979). The Self Concept: Theory, Measurement, Development and Behaviour. London: Longman.

Debatin, Bernhard (1994). Zur Modellierung der Mensch-Computer-Interaktion. Berlin: Technische Universität Berlin.

Der Tagesspiegel, 11 December 1993, 12.

Eden, Dof (1986). Organizational development and self-fulfilling prophecy. Boosting productivity by raising expectations. Journal of Applied Behavioral Science 22 (1), 1-13.

Epstein, Samuel (1979). Entwurf einer integrativen Persönlichkeitstheorie. In SelbstkonzeptForschung, Sigrun-Heide Filipp (ed.), 15-45. Stuttgart: Klett.

Figge, Udo L. (1991). Computersemiotik. Zeitschrift für Semiotik 13 (3, 4), 321-330.

Friedman, Stanley P. (1986). Ronald Reagan: His Life Story in Pictures. New York: Dodd and Mead.

Gergen, Kenneth (1971). The Concept of Self. New York: Holt, Rinehart and Winston.

James, William (1890). Principles of Psychology, vol. 1. New York: Holt.

Kantrowitz, Barbara (1994). Men, women and computers. Newsweek May 16, 48-52.

Khan, M. Masud R. (1977). D. W. Winnicott. In Die Psychologie des 20. Jahrhunderts III: Freud und die Folgen II, 348-382. Zurich: Kindler.

Kirsch, Irving (1985). Response expectancy as a determinant of experience and behavior. American Psychologist 40, 1189-1202.

Laing, Ronald D. (1960). The Divided Self. An Existential Study in Sanity and Madness. London: Tavistock.

Laing, Ronald D.; Phillipson, Herbert; and Lee, A. Russell (1966). Interpersonal Perception. London: Tavistock. 
Leu, Hans Rudolf (1993). Wie Kinder mit Computern umgehen. Munich: Juventa.

Ludwig, Peter H. (1991). Sich selbst erfüllende Prophezeiungen im Alltagsleben. Stuttgart: Verlag für Angewandte Psychologie.

Maaß, Susanne (1984). Mensch-Rechner-Kommunikation: Herkunft und Chancen eines neuen Paradigmas. Unpublished Ph.D. dissertation, University of Hamburg.

Mead, George H. (1934). Mind, Self and Society, ed. by Charles W. Morris. Chicago: University of Chicago Press.

-(1964). Self. In George Herbert Mead on Social Psychology. Selected Papers, Anselm Strauss (ed.), 199-246. Chicago: University of Chicago Press.

Merton, Robert K. (1948). The self-fulfilling prophecy. Antioch Review 8, 193-210.

Mummendey, Hans Dieter (1990). Psychologie der Selbstdarstellung. Göttingen: Hogrefe.

Noonan, Peggy (1990). What I Saw at the Revolution: A Political Life in the Reagan Era. New York: Ivy Books.

Paetau, Michael (1989). Strukturen und Prozesse der Mensch-Maschine-Kommunikation. Zur soziologischen Analyse eines software-technischen Gestaltungspotentials. Unpublished Ph.D. dissertation, University of Bremen.

Paetau, Michael and Piper, Michael (1985). Computer und menschliche Kommunikation. Beitäge zur techniksoziologischen Erforschung computergestützter Kommunikation. St. Augustin: Arbeitspapiere der GMD.

Posner, Roland (1993). Believing, causing, intending: The basis for a hierarchy of sign concepts in the reconstruction of Communication. In Signs, Search and Communication: Semiotic Aspects of Artificial Intelligence, René J. Jorna, Barend van Heusden, and Roland Posner (eds.), 215-270. Berlin: de Gruyter.

-(1994). Der Mensch als Zeichen. Zeitschrift für Semiotik 16 (3, 4), 195-216 [English transl.: Humans as signs: iconic and indexical. In Indexicality: Papers from the Symposium Indexikala Tecken, Christiane Pankow (ed.), 97-117. Göteborg: SKI 1955].

-(1995). Zur Genese von Kommunikation: Semiotische Grundlagen. In Kommunikation und Humanontogenese, Karl-Friedrich Wessel and Frank Naumann (eds.), 384-429. Bielefeld: Kleine.

-(1996). The self and its presentation in humans and computers. In Semiotics around the World. Synthesis in Diversity. Proceedings of the Fifth Congress of the International Association for Semiotic Studie, Berkeley, 1994, Irmengard Rauch and Gerald F. Carr (eds.), 793-796. Berlin: Mouton de Gruyter.

Public Papers of the Presidents of the United States: Ronald Reagan, January 1 to June 29, 1984. Washington, D. C.: United States Government Printing Office 1986.

Reagan, Ronald W. (1965). Where's the Rest of Me? An Autobiography with Richard G. Hubler. New York: Hawthorn [new Edition: New York: Karz 1981].

-(1990). An American Life. New York: Simon and Schuster.

Ripper, Heiko (1998). Der große Kommunikator: Die Medienstrategie Ronald Reagans im Kontext der US-Präsidenten. Munich: Alber.

Rosenthal, Robert (1968). Self-fulfilling prophecy. Psychology Today 2, 46-51.

- (1975). Der Pygmalion-Effekt lebt. Psychologie heute 6, 18-21, 76-79.

-(1976). Experimenter Effects in Behavioral Research. New York: Halsted.

Rosenthal, Robert and Jacobson, Lenore (1968). Pygmalion in the Classroom. New York: Holt, Rinehart and Winston.

Schiller, Friedrich (1962 [1795]). Briefe über die ästhetische Erziehung des Menschen. Die Horen 1, 2 and 6. New Edition in Sämtliche Werke, vol. 5, third edition, 570-808. Munich: Hanser.

Sommer, Carlo M. and Wind, Thomas (1991). Die Mode: Wie das Ich sich darstellt. Weinheim: Beltz. 
Suls, Jerry M. (ed.) (1982). Psychological Aspects of the Self, 3 vols. Hillsdale, NJ: Lawrence Erlbaum.

Woolley, Benjamin (1992). Virtual Worlds: A Journey in Hype and Hyperreality. London: Blackwell.

Roland Posner (b. 1942) is Distinguished Professor of Linguistics and Semiotics at the Research Center for Semiotics at the Technical University of Berlin. He is also the President of the International Association for Semiotic Studies 〈posner@kgw.tu-berlin.de >. His research interests include the philosophy of science, linguistic pragmatics, theory of literature, and semiotics of culture. His major publications include Theorie des Kommentierens. Eine Grundlagenstudie zur Semantik und Pragmatik (1972), Rational Discourse and Poetic Communication (1982), What is Culture? Towards a Semiotic Explanation of Anthropological Concepts (1989), Believing, Causing, Intending: The Basis for a Hierarchy of Sign Concepts in the Reconstruction of Communication (1993), and Semiotics: A Handbook of the Sign-Theoretic Foundations of Nature and Culture (with Klaus Robering and Thomas A. Sebeok) (1997f.). 